\title{
PHYLOGENETICS OF THE EARLY PALEOZOIC ARCHAEOGASTROPODA
}

\author{
WAGNER, Peter J., III. Dept. of the Geophysical Sciences, University of Chicago, \\ 5734 S. Ellis Ave, Chicago, IL 60637 U.S.A.
}

The Archaeogastropoda are one of the most abundant orders of the Paleozoic, but they have received surprizingly little systematic analysis. I have conducted a cladistic analysis of archaeogastropod species appearing during the initial radiation of the clade during the latest Cambrian through the Ordovician. The analysis included over 100 species. Most specimens were from North America, but some European and Asian material was included. The hypothesized phylogeny also includes an additional $\mathbf{4 0}$ Ordovician species from a previous cladistic work on a single family (the Lophospiridae), and only the stem members of this clade were included here.

The analysis used 54 meristic and 12 morphometric traits encompassing 154 character states. This seemingly large number of character states for a group considered character-poor can be attributed to: 1) the breadth of morphologic diversity produced during the initial phases of the clade's radiation, resulting in nearly all conceivable morphologies being included here; and 2) the high number of character states for "types" of selenizones and sinuses, morphologies absent on most extant gastropods.

The results of the analysis suggest the following:

1. There were two large clades present by the Early Ordovician that most closely correspond to present definitions of the Murchisonoidea and Euomphaloidea. The clades shared an anisostrophically coiled common ancestor and thus were not derived separately from bellerophonts. However, the Macluritidae appear to have been derived separately from bellerophonts, corroborating a widely held hypothesis.

2. Early Paleozoic species presently considered "pleurotomaroids" comprise a polyphyletic assemblage, with the major families independently derived from either the murchisonoid clade (the Eotomaridae, Lophospiridae and Phanerotrematidae) or from the euomphaloid clade (the Liospiridae, Luciellidae and post-Middle Ordovician members of the Raphistomatidae). It had been assumed previously that pleurotomaroids represent the least-derived anisostrophically coiled gastropods, as well-developed selenizones and sinuses were considered primitive traits. However, those features actually represent derived conditions of the Ordovician that appear to have been secondarily lost in later lineages; thus seemingly "modern" appearing early Paleozoic species often simply retained non-derived conditions. As the Mesozoic Pleurotomaria can not be linked with any Early Paleozoic clades, there is no basis for classifying early Paleozoic gastropods in the Pleurotomaroidea.

3. The Subulitoidea and Loxonematoidea (which may be ancestral to the Caenogastropoda) evolved separately from murchisonoids. The origins of the Trochoidea are not clear. If the Holopeidae represent the stem members of the Trochoidea, then trochoids evolved from euomphaloids. However, the Platyceratidae also have been linked with trochoids. The earliest known members of that group possess many unique homologies and no obvious synapomorphies with any other archaeogastropods. The taxon can not be linked reliably with holopeids or any other taxon included in this study, and I do not discount the possibility that platyceratids were evolved separately from bellerophonts.

4. Gross shell convergences abound, as turritelliform and planispiral-tohyperstrophic shells both evolved at least four times. However, the combinations of character states used to achieve these gross morphologies differ among clades, allowing "homoplasies" of character complexes to be recognized. 